\title{
Clareamento gengival: ensino e etnocentrismo
}

\author{
Gingival bleaching: teaching and ethnocentrism
}

Edson Daruich Bolla ${ }^{1}$ PauleteGoldenberg ${ }^{2}$
${ }^{1}$ Departamento de Psicologia da Educação, FaculdadedeEducação, UNICAM P. Av. Bertrand Russel 801, Cidade Universitária "Zeferino Vaz". 13083-865 Campinas SP.edsonbolla@bol.com.br 2 Programa de Pósgraduação em Ensino em Ciências da Saúde, Centro deDesenvolvimento do Ensino Superior em Saúde, UniversidadeFederal deSão Paulo.
Abstract The aim of this study was to identify buccal/gingival cosmetic dentistry patterns subjacent to formation and professional practice of the dental surgeon from the ethnocentrism point of view. Thisis an exploratory study with a qualitative approach based on the thematic analysis. Initially a documental analysis was carried out. Thereafter, dental surgeons were interviewed and semi-structured questions were applied. In the Periodontal teaching field, this study showed that the presence of racial melanosis is omitted or treated as an alteration in the normality patterns and it is considered anti-aesthetic. All the intervi ewers learnt how to practice gingival bleaching in the post-graduation courses, they were all encouraged to offer this cosmetic dentistry procedure with the opportunity of obtaining a beautiful and healthy smile, thus assuring the belief of the Caucasian racial aesthetic superiority. This study make us think that the offer of gingival bleaching is oriented by the Caucasian pattern of beauty evidencing the ethnocentric character of this procedure.

Key words Ethnocentrism, Whitening, Gingival Bleaching
Resumo 0 estudo objetivou identificar os padrões de estética bucal/gengival subjacentes à formação e prática profissional do cirurgião-dentista, na perspectiva do etnocentrismo. A partir da análise documental e da realização de entrevistas (semiestruturadas) com cirurgiões dentistas formados há dez ou maisanos, o estudo recorreu a uma abordagem qualitativa, ancorada na análise temática. No âmbito do ensino da periodontia, o estudo evidenciou que a presença da pigmentação fisiológica é omitida ou tratada como uma alteração de normalidade el ou antiestética. Todos os entrevistados aprenderam a realizar o clareamento gengival em nível de pós-graduação, sendo estimulados a ofertar tal procedimento em nome de um sorriso saudável e bonito. Diante da supervalorização da eficiência da técnica, ressalta a ausência da discussão da questão estética na perspectiva étnica. Parece quea oferta do clareamento gen gival se faz norteada pelo padrão branco de beleza, evidenciando 0 caráter etnocêntrico do procedimento.

Palavras-chave Etnocentrismo, Embranquecimento, Clareamento gengival 
Introdução

Objetivando identificar padrões de estética bucal/gengival subjacentes à formação e prática profissional do cirurgião-dentista, focalizamos, no presente estudo, o exercício do clareamento gengival na perspectiva do etnocentrismo.

Segundo Thomaz" ${ }^{1}$ o etnocentrismo " [...] consiste em julgar como certo ou errado, feio ou bonito, normal ou anormal os comportamentos e as formas de ver o mundo dos outros povos a partir dos próprios padrões culturais [...]". Ainda que caminhem juntos, etnocentrismo e racismo não são a mesma coisa. Lévi-Strauss, citado por $\mathrm{Machado}^{2}$, afirma que não se pode confundir o racismo - considerado como uma [...] doutrina falsa que pretende ver nas características intelectuais e morais atribuídas a um conjunto de indivíduos [...] o efeito necessário de um patrimônio genético comum - com a atitude de indivíduos ou grupos cuja fidelidade a certos valores os torna parcial ou totalmente insensíveis a outros valores. Entendendo que as posturas etnocêntricas podem evoluir para um racismo, particularmente diante do intenso processo de inclusão-exclusão sociais em nosso meio, consideramos a definição de M unanga?: "O racismo é uma crença na existência das raças natural mente hierarquizadas pela relação intrínseca entre o físico e o moral, o físico e o intelecto, o físico e o cultural".

No Brasil, como refere Carneiro ${ }^{4}$, tem sido usual sustentar a imagem de uma nação cordial, caracterizada por apresentar um povo pacífico e sem preconceito de "raça", sendo que durante anos alimentamos a idéia de que vivemos uma democracia racial. Entretanto, tal democracia racial não existe, haja vista as desigualdades e limites de oportunidades oferecidas aos negros ao longo da história.

De acordo com Soligo 5 , em 1501, se inicia a história do negro no Brasil. A transição do trabalho indígena para o africano explica-se pelo tráfico negreiro queabriu caminho a um negócio rendoso, de alto valor comercial6.

Segundo Schwarcz, citado por $\mathrm{Haag}^{7}$, no final do século XIX, se afirmava que a mistura racial era prejudicial e que um país formado por muitos segmentos raciais estava fadado à decadência. Segundo a autora, Nina Rodrigues, assumindo o "darwinismo racial", preconizava a separação racial: a seleção natural daria cabo, no processo competitivo, dos segmentos inferiores que seriam postos sob controle ou eliminados. No período pós-abolicionista- expressando uma modalidade de racismo à brasileira, segundo Domingues $^{8}$ - 0 branqueamento era apresentado como um processo irreversível no país. Pelas estimativas mais "confiáveis", o tempo necessário para a extinção do negro em terra brasileira oscilaria entre cinquenta e duzentos anos. Bernardino ${ }^{9}$ afirma que, ao lado do mito da democracia racial, arquitetou-se no Brasil o ideal do branqueamento como uma política nacional de promoção da imigração européia que visava suprir a escassez de mão de obra resultante da abolição e modernizar o país através da atração de mão de obra européia.

A ideologia do embranquecimento apresenta o branco como modelo de beleza e de sucesso. A hierarquização das pessoas em termos de sua proximidade a uma aparência branca ajudou a fazer com que indi víduos de pigmentação escura desprezassem a sua origem africana, cedendo assim à forte pressão do branqueamento, levando-os a fazer o melhor possível para parecerem mais brancos ${ }^{10}$.

Segundo Carneiro ${ }^{4}$, existe um preconceito velado em nossa sociedade, no qual dificilmente encontramos nas falas dos indivíduos a sua explicitação. Tal pensamento está nas formas de agir, nas opiniões e opções que os sujeitos fazem julgando os negros - como inferiores - pela cor de sua pele e não pela sua capacidade, índole e caráter. Para a autora, no Brasil, tem sido usual sustentar a imagem de um país cordial, caracterizado pela presença de um povo pać́fico, sem preconceito deraça e religião.

Tal negação do racismo acaba por propiciar a hegemonia do branco e, nesse âmbito, se inscreve a formação do clareamento gengival, apresentado aos discentes de odontologia como uma técnica resultante dos avanços profissionais.

Os primeiros cursos de graduação em odontologia, no Brasil, foram criados em outubro de 1884, nas Faculdades de M edicina da Bahia e do Rio de Janeiro. Em 1898, foi fundada a Escola (privada) Livre de Farmácia e Odontologia em São Paulo, sendo que em 1933 se concretiza a separação dos cursos de odontologia das escolas médicas 6 .

No processo de reorganização do ensino mé dico nos Estados Unidos e Canadá, o Relatório Flexner, publicado em 1910, refletiu no ensino superior, defendendo a inserção das escolas de medicina nas instituições universitárias. 0 relatório previa a criação de departamentos em lugar de cátedras e o desenvolvimento de ensino e pesquisa, destacando a formação em ciências. Tais disposições comportariam a criação do ci- 
clo básico antecedendo ao ciclo profissionalizante, assim como a incorporação do hospital como campo de treinamento na formação de médicos. A reprodução deigual movimento no âmbito da odontologia, deacordo com Gies, citado por Oliveira ${ }^{6}$, constituiria a base para o desenvolvimento tecnológico ao lado do desenvolvimento das especialidades que consubstanciariam o caráter tecnicista da formação em odontologia em nosso meio.

No decorrer da trajetória desencadeada a partir da reforma universitária (que se instala em 1968), reafirma-seo desenvolvimento da pesquisa com a instalação da pós-graduação que suportaria propostas da formação especializada de recursos humanos.

$N$ as décadas seguintes, no contexto da intensificação da gl obalização, renovam-seas propostas relativas ao processo ensino/aprendizagem, sendo preconizadas reformas curriculares, asse gurada a flexibilidade no tocanteà sua organização. A Lei de Diretrizes e Bases da Educação Nacional ${ }^{11}$ de 1996, destacando anecessidadedeatender às demandas sociais, no artigo 43, propõe estimular a criação cultural e o desenvolvimento do espírito crítico e do pensamento reflexivo. Tal lei dispõe sobre a extinção dos currículos mínimos, desencadeando as proposições em torno de mudanças curriculares explicitadas pelas Diretrizes Curriculares Nacionais (2001). Desde o final de 2001, os cursos de odontologia começaram a buscar soluções, cumprindo as exigências de elaboração de projetos político-pedagógicos, dando conta de mudanças curriculares envolvendo a profissionalização do trabalho docente.

Para Péret e Lima ${ }^{12}$, a formação do professor de odontologia tem sido baseada na racionalidade técnica, fundada na filosofia positivista. Assim, são considerados profissionais competentes aqueles que solucionam problemas instrumentais, mediante aplicação de teorias e práticas derivadas de conhecimento sistemático. 0 conhecimento emergente das particularidades dos contextos sociais e culturais dos cidadãos não tem sido enfocado nesse modelo, o que induz à necessidade de repensar a formação dos professores em uma dimensão humana ecrítica. Isso seaplica à ausência de considerações de questões relativas às desi gualdades sociais na formação odontológica ao lado da supervalorização da técnica. N este sentido, coloca-se como exemplar a problemática da estética enquanto expressão de preferências no convívio com a diferença.

Segundo Bertollo e Oliveira ${ }^{13}$, a percepção da beleza é individual, ao mesmo tempo em que se inscreve num quadro de referência cultural. Segundo $\mathrm{M}$ andarino ${ }^{14}$, a estética é pessoal e subjetiva, variando conforme a época e a região em que as pessoas vivem. Para ele, os padrões estéticos da sociedade atual exigem um sorriso bonito e harmonioso, incentivando a procura de tratamento odontológico para correções de imperfeições dentárias.

$K a t z^{15}$ afirma acreditar que a beleza é uma conquista e não um dado genético, pois ela se conquista dentro de um grupo social. Afirma, ainda, queé sempreuma luta muito difícil alcançar o que deve ser o corpo para corresponder a um padrão, lembrando que a conquista da belezaéinfinita: éum movimento incessantena busca de uma perfeição que não é nem definida.

Discutindo a questão estética da população negra, Gould ${ }^{16}$, ao comentar sobre as idéias de alguns abolicionistas, dentreeles Benjamin Franklin, relata que, mesmo entreaqueles que consideravam a inferioridade dos negros como puramente cultural, a frequência do juízo estético que determinava a superioridade da população branca em detrimento das demais era surpreendente.

Em resposta à busca pela "perfeição não definida"17, mas associada ao padrão branco de beleza, éque muitas técnicas terapêuticas de modificações de caracteres presentes em pessoas não brancas têm sido desenvolvidas com o intuito de assemelhá-las aos padrões estéticos vigentes na sociedade ocidental: o padrão estético da população branca (branqueamento estético).

Domingues discute o quedenomina de"branqueamento estético" no Brasil. Para ele, a ideologia do branqueamento se expressava no terreno estético. 0 modelo branco de beleza, considerado padrão, pautava o comportamento e a atitude de muitos negros assimilados. Tal ideologia foi um fetiche muito eficaz na alienação do negro. Oficializou a brancura como padrão de beleza, o que representou um entrave para a formação positiva da autoestima do negro.

Os avanços da tecnologia e da pesquisa no ramo da cosmética, na atualidade, vêm permitindo o refinamento e a perpetuação do branqueamento estético. A odontologia passou, segundo $M$ andarino, a seguir caminhos que vão além de técnicas restauradoras, buscando restabelecer a função, a estética eo bem-estar do cliente, devolvendo-Ihe a autoestima, o prazer em sorrir, ou seja, o prazer em viver.

A propósito da busca contemporânea pela renovação do ensino, reafirma-se a preocupação com os padrões deestética bucal/gengival que orientam a formação prática do cirurgião- den- 
tista, tendo por suspeita que a realização do clareamento gengival - envolvendo uma postura etnocêntrica - se faz norteada pelo padrão branco de beleza. N este sentido é que nos propomos a trabalhar os referenciais de beleza vigentes no ensino da periodontia no tocante ao clareamento gengival, assim como identificar as concepções de estética bucal do cirurgião-dentista subjacentes à prática do referido procedimento .

\section{M étodos}

0 presente estudo, em caráter exploratório, envolveu três movimentos investigativos: (1) caracterização do clareamento gengival no plano do ensino e da aprendizagem - exclusivamenteda disciplina de periodontia; (2) identificação dos conceitos de estética bucal/gengival subjacentesà prática do clareamento gengival, entre negros e caucasianos; (3) qualificação, tanto da formação como da prática, do clareamento gengival na perspectiva do etnocentrismo.

No tocante ao ensino da periodontia, o estudo partiu da investigação documental, sendo consultadas as ementas da disciplina de periodontia de duas escolas de odontologia do Estado deSão Paulo: uma pública eoutra privada; livros didáticos da área de periodontia; publicações em bases de dados através da Biblioteca Virtual de Saúde.

$\mathrm{Na}$ análise documental, foram priorizados os objetivos e referências bibliográficas da disciplina de periodontia nos cursos de graduação deodontologia de duas instituições, os padrões estéticos vigentes, as técnicas preconizadas para a realização do clareamento gengival, na periodontia, as justificativas apresentadas para a realização da práticadetal procedimento cirúrgico entrepacientes negros e a abordagem da questão racial.

As informações acerca do ensino da periodontia no tocante ao clareamento gengival foram complementadas com entrevistas semiestruturadas, com profissionais da área de odontologia. Como critério de inclusão na população de estudo, consideramos cirurgiões-dentistas que tivessem concluído a graduação há dez anos ou mais eque realizavam o clareamento gengival em seus consultórios e/ ou clínicas. Participaram do estudo quinze profissionais.

A apreensão das concepções de beleza do cirurgião-dentista, no tocanteao clareamento gengival, levou em conta as informações obtidas a partir das entrevistas realizadas, nas quais se priorizou o perfil dos entrevistados (gênero, idade, tempo de formação, natureza da instituição formadora e titulação), identificação dos motivos que levaram os entrevistados a optar pela odontologia e apreensão e caracterização dos padrões estéticos vigentes na formação e na prática dos cirurgiões-dentistas do bairro do Tatuapé.

Tanto em relação à consideração dos documentos como das respostas registradas nas entrevistas, realizou-se a análise de conteúdos para efeito de apresentação dos dados e, dentre suas modalidades, optou-se pela análise temática, tendo por referência a perspectiva do etnocentrismo.

O projeto foi aprovado pelo Comitê de Ética da Unifesp, os entrevistados assinaram um termo de consentimento livre eesclarecido (TCLE) e o anonimato destes foi assegurado.

\section{Resultadosediscussão}

Formação do clareamento gengival:

análise de documentos

A disciplina de periodontia, em ambas escolas consultadas, tem como propósito o embasamento teórico-prático do aluno. No que tange à saúde do paciente, a preocupação vai além do tratamento da doença já instalada, sendo assinalada a capacidade de prevenir a doença periodontal. No caso da escola privada, destacou-se a preocupação com o desenvolvimento dos aspectos afetivos relacionados ao atendimento ao paciente. Em ambas ementas, a abordagem formal da questão estética está ausente.

Três livros-textos da periodontia foram localizados na biblioteca da Faculdade de O dontologia da USP, sendo focalizado o olhar para a descrição da anatomia macroscópica da gengiva e o que estas obras consideravam como normal, fisiológico.

No "Tratado dePeriodontia Clínica el mplantologia Oral", de Lindhe ${ }^{17}$, o primeiro capítulo do livro, denominado "Anatomia do Periodonto", descrevea anatomia macroscópica da gengiva, no quetange à cor desta, da seguintemaneira: A gengiva é a parte da mucosa mastigatória que cobre o processo alveolar e circunda a porção cervical dos dentes. [...] Em direção à coroa, a gengiva de cor rósea termina na margem gengival livre, que possui um contorno festonado. [...] A gengiva livre, que tem cor rósea, superfície opaca e consistência firme, compreende o tecido gen gival das partes vestibular e lingual ou palatina dos dentes.

[...] Com textura firme e cor rósea, a gengiva inserida com frequência mostra uma superfícieque 
apresenta uns pontilhados delicados, o quelheconfere 0 aspecto de casca de laranja [ grifo nosso].

Em nenhum momento do primeiro capítulo, tal obra citou a existência da pigmentação fisiológica (melanina - ou melanose racial) predominante na população negra, enquanto que "cor rósea" apareceu três vezes, sugerindo ser esta a condição normal, referenciando o padrão anatômico predominante na população branca.

No livro "Periodontia Clínica deGlickman" de Carranza Jr. ${ }^{18}$, a abordagem da cor da gengiva está descrita também no capítulo 1, no tópico "Os Tecidos do Periodonto". Tal temática é descrita da seguinte maneira: A cor da gengiva inserida emarginal égeralmentedescrita como rosa-claro, eéproduzida pela vascularização, [...]. A cor varia em diferentes pessoas e parece estar correlacionada à pigmentação cutânea. É mais clara nos indivíduos louros de pele branca do que nos morenos.

Após tal descrição, a obra apresenta, ainda no mesmo capítulo, um tópico denominado "Pigmentação Fisiológica (M elanina)", no qual afirma que: A melanina [...] é responsável pela pigmentação normal da pele, gengiva e membrana mucosa bucal. Está presente em todos os indivíduOS, [...] A pigmentação melânica na cavidadebucal é acentuada nos negros.

Diferentemente da obra anteriormente discutida, que simplesmente omitiu a existência ea normalidade da melanose racial, nessa segunda obra consultada, já existem referências sobre tal característica no primeiro capítulo. Entretanto, é importanteverificar que o autor descreveu a gengiva como um tecido de cor rósea e apresentou ao leitor algumas informações pertinentes a esse tecido. Somente após ter concluído tal raciocínio, o conceito da pigmentação fisiológica é introduzido, afirmando que esta se apresenta, acentuadamente, na população negra.

No terceiro livro consultado, "PeriodontiaClínica", de Machado19, o capítulo 1, "Anatomia do Periodonto", descreve a anatomia macroscópica da gengiva da seguinte maneira: $\mathrm{Na}$ boca, encontramos três tipos distintos de mucosas: especializada, mastigatória e de revestimento. [...] A gengiva recobre o processo alveolar que circunda os dentes: em indivíduos caucasianos, possui coloração rósea e consistência firme; em negros e asiáticos, apresenta também significativa quantidade de melanina.

Tal obra reconhece desde o início o queénormal em distintos grupos étnicos. Para os caucasianos, uma gengiva rosa e, para os negros, uma gengiva queapresenta também significativa quantidade de melanina. Sem omissões, sem confundir/associar a melanose racial como um desvio da normalidade e sem hierarquizar as informações.
Focalizando a consideração da questão racial nos textos sobre 0 clareamento gengival, registramos no "Compêndio Terapêutico Periodontal" de Lascal ${ }^{20}$ que, no capítulo sobre "Gengivectomia/gengivoplastia", o autor explicita que a gengivoplastia“[...] visa, única e exclusivamente, à obtenção de uma arquitetura gengival anatomofisiológica". Dentre as indicações de tal técnica, a "eliminação de pigmentação melânica" se faz presente.

Quando da descrição da eliminação da melanose racial, 0 autor afirmou que $A$ presença da melanina, sob diversas formas, no tecido gengival de pacientes melanodermos, não é de maneira alguma, sinal de patologia, apenas uma variação da normalidade. N esses casos a indicação da gengi voplastia se dá apenas por razões estéticas.

Primeiramente, o texto explicitou quetal técnica cirúrgica "visa, única e exclusivamente, à obtenção de uma arquitetura gengival anatomofisiológica". Ou seja, devolver à gengiva forma e funções normais. Esta mesma abordagem se expressou nas indicações da técnica envolvendo a eliminação da pigmentação melânica (melanose racial) que peseo caráter exclusivamente estético de tal procedimento. Ficou implícito que o propósito de devolver a forma normal à gengiva está associada à eliminação da melanose racial. Considerando que tal procedimento cirúrgico visa devolver forma e função normais, o autor associa a estética à saúde.

Em relação ao levantamento de periódicos da área de periodontia, encontramos um artigo sobre o clareamento gengival, referenciado na Lilacs ena BBO com o título "Três diferentes técnicas cirúrgicas empregadas no clareamento gengival" de Amorim Lopes, Lopes, Silva e Almei$\mathrm{da}^{21}$. Os autores preconizam diferentes técnicas para a realização do clareamento gengival, destacando a praticidade dos procedimentos, aparel hagem simples, baixos efeitos colaterais e resultados alcançados.

No artigo, encontramos duas referências explicitando a opinião dos autores quanto à presença da melanose racial. $\mathrm{Na}$ sinopse, referem que "A hiperpigmentação gengival pode causar problemas estéticos, especialmente em pacientes com sorriso gengival [...]".

A pós a descrição deum caso clínico, afirmam que "[...] 0 sorriso agora parece estar mais atraente, satisfazendo completamente a expectativa da paciente".

Os autores explicitaram, nestasfal as, queacreditam que a hiperpigmentação gengival é uma característica antiestética e que os pacientes que se sujeitam à melanoplastia (cirurgia para remo- 
ção da melanose racial) ficam mais atraentes, logo, mais bonitos.

De acordo com Rocha22, os livros didáticos, em função mesmo do seu destino e de sua natureza, têm um valor de autoridade, ocupando um lugar de supostos donos da verdade. Suas informações obtêm tal valor de verdade pelo simples fato de que quem sabe seu conteúdo é aprovado. Seu saber tende a ser visto como algo rigoroso, sério e científico. Os estudantes são testados em face do seu conteúdo, o que faz com que as informações neles contidas acabem se fixando no fundo da memória de todos nós. Com ela, se fixam também imagens etnocêntricas.

A maioria das obras consultadas nesta análise de documentos sinaliza que o ensino da periodontia, no que diz respeito à descrição da anatomia macroscópica do periodonto - destacando a gengiva - e das indicações de remoção da pigmentação melânica (fisiológica) privilegiam as características da população branca.

Formação do clareamento gengival: entrevistas

Com relação ao perfil dos entrevistados, observamos um grande contingente feminino, formados entre dez equinze anos e provenientes de escolas públicas e privadas.

Quase $50 \%$ dos sujeitos da amostra responderam ter afinidade com a área da saúde. Prazer em cuidar, a presença de algum familiar exercendo a odontologia e gostar de trabalhar com a estética também fizeram parte dos argumentos relevantes para a escolha da odontologia entre os entrevistados. Trazendo implícita a crença na supremacia estética da população branca, o entrevistado refere: Eu acho que as pessoas devem se sentir bonitas. É importante. Eu gosto de poder contribuir para que isso aconteça. Clarear a gengiva é uma das coisas que tornam a pessoa mais bonita. (Entrevistado C)

A questão da estética nos cursos de odontologia está presente, sendo referenciada por múltiplas disciplinas. Na periodontia, ela se coloca prioritariamente relacionada à preservação de uma gengiva saudável, sendo por todos ressaltada sua importância para um sorriso bonito, ao qual se associa a importância da estética na vida social, pessoal e profissional. Associando 0 aspecto saudável à beleza, os entrevistados afirmaram que: $\mathrm{H}$ ojea sociedade dá uma ênfase grandeà questão estética. Ter uma gengiva saudável, sem inflamações, sem retrações, é desejado. Para se ter um sorriso bonito, temos que ter uma gengiva bonita também. (Entrevistado C)
Perguntados sobre o que Ihes foi dito, durante a graduação, a respeito de um sorriso bonito, onze entrevistados fizeram referência à coloração branca dos dentes associada a tamanhos e formas regulares, além da ausência de cáries; nove entre eles fizeram referência à gengiva de cor rósea, saudável e sem edemas; e três entrevistados explicitaram gengivas sem manchas.

Tais resultados mostram que mais da metade dos entrevistados recordavam ter aprendido que um sorriso bonito era um sorriso associado a uma gen giva livre de pigmentos e com coloração rósea. Valorizando a gengiva característica da população branca, estas lembranças sinalizaram para uma postura etnocêntrica, visto que a gengiva da população negra é por vezes pigmentada e tem uma coloração que tende para tons mais escuros. A propósito, são significativas as falas: U ma gengiva rosa, sem manchas, com aspecto saudável, com "cara" de saúde e dentes muito brancos, com tamanhos regulares, com forma bonita. Socialmente legal. (Entrevistado C)

Focalizando, especificamente, a temática do clareamento gengival, perguntamos aos entrevistados se esse tema havia sido abordado na graduação, em que condições e em que ocasi ão eles aprenderam a realizar a(s) técnica(s). A penas três entrevistados afirmaram recordar referências ao tratamento detal temática na graduação, evidenciando que o clareamento gengival foi pouco discutido nos cursos de odontologia entre alunos formados até 1996.

Os três dentistas que se recordaram da abordagem do clareamento gengival no curso de graduação mencionaram queelefoi apresentado como uma intervenção puramente estética, descolada da questão racial. As discussões sobre o procedimento do clareamento gengival se davam no plano técnico-biológico: Q uanto à abordagem dos professores, eles não ficavam falando que era coisa de negro, que era uma questão do branco ser mais bonito que o negro e etc. Eles simplesmente falavam das técnicas, das indicações, de como fazer e etc. U ma coisa éfato: uma gengiva sem melanoseémais bonita que uma com melanose. (Entrevistado $\mathrm{H}$ )

As falas do Entrevistado $\mathrm{H}$ revelam a aparente neutralidade da técnica. Q uando este entrevistado afirma que uma gengiva sem melanose é mais bonita, identificamos a naturalização do padrão estético vigente da população branca.

Todos os entrevistados afirmaram queaprenderam a técnica da remoção da pigmentação fisiológica após a conclusão da graduação. Para estes dentistas, 0 aprendizado detal técnica ocorreu em nível de pós-graduação. 
Os entrevistados afirmaram, também, que nunca participaram de discussões acerca das características da população negra associadas à melanose racial e sua remoção. As justificativas se pautavam pela argumentação em torno do padrão de estética almejado em nomede um sorriso bonito: Pra dizer a verdade, não me recordo nem uma vez de termos discutido esses problemas. N osso curso é da área da saúde, não de psicologia. Quem tem que discutir isso é o pessoal das humanas. Nosso papel é outro. Discutimos saúde, não neuroses. Se os negros se sentem inferiores, quem resol veisso são os psi cól ogos. Nós cuidamos da saúde. (Entrevistado D)

A belezase circunscreveneste conjunto derespostas a uma questão individual como se a subjetividade não tivesse relação com as condições socioculturais na qual ela se desenvolve. $\mathrm{Na}$ verdade, os entrevistados não associam a configuração de padrões estéticos no âmbito dos grupos étnicos. N esse sentido, não associam o clareamento gengival à questão racial.

Quando o Entrevistado D afirmou que os negros "se sentem inferiores", ao mesmo tempo em que reconhece a existência de desigualdades sociais e exclusão, ancoradas na hierarquização dos indivíduos (como colocam Munanga ${ }^{3}$, Guimarães ${ }^{23}$ e Soligo ${ }^{5}$, entre outros); ele atribui o sentimento de inferioridade aos próprios negros. Ao colocar que o problema de sentimentos não constitui questão a ser considerada pelos dentistas, o entrevistado não situa a inferioridade no plano das relações sociais e de poder existentes na sociedade.

Em relação à convivência com os negros durante a graduação, os entrevistados afirmaram que em suas turmas havia de dois a três mulatos/negros, sendo que não necessariamente nas respectivas turmas. Quatro afirmaram não se recordar de alunos negros no curso. Na pós-graduação, apenas dois entrevistados afirmaram que havia dentistas "mulatos" em suas turmas.

Estes dados são reveladores do elitismo do ensino e das limitadas oportunidades de acesso do negro ao ensino superior, em meio à exclusão social. Uma pesquisa realizada pelo Instituto Nacional de Estudos e Pesquisas Educacionais Anísio Teixeira (Inep) ${ }^{24}$ revelou quea média geral de representação da população negra nos cursos universitáriosera deapenas 3,6\%, esomente0,8\% dos alunos matriculados nos cursos de odontologia de escolas públicas e privadas do Brasil eram negros. A propósito, são ilustrativas as falas: $\mathrm{Na}$ graduação, havia uma moça negra, na minha especialização, não. Ela era tranquila, não ficava se preocupando. E era boa aluna também. Lembro que ela tinha boas notas. $N$ ão tive muito contato com ela. (Entrevistado F)

No meu curso de aperfeiçoamento tinha [um aluno negro], mas era um rapaz mulatinho, não negro, daqueles super escuros. Ele era até bonitinho, sabia? Tinha o cabelo liso, não era "pichaim", tinha os dentes bonitos. N ão lembro de eleter falado al guma coisa sobreo clareamento gengival. $\mathrm{N}$ em sei sea gengiva deleera manchada. Seera não dava para perceber. M as elenão era negro, era só mulato. (Entrevistado I)

No plano discursivo, ao lado do reconhecimento da pequena presença de negros, estas falas remetem a um preconceito velado, explicitado no espanto das considerações a respeito dos colegas negros, expresso nas construções adversativas. Partilhando de um convívio no qual os negros e/ou mulatos não pareciam questionar a própria negritude, os entrevistados se referiram aos alunos negros dizendo que "e (ela) era boa aluna" ou "ele era até bonitinho, sabia?" "tinha o cabelo liso, não era 'pichaim'", etc. Ao tecer tais comentários, eles assumiam a valorização negativa da diferença e o posicionamento de desagrado em relação aos traços étnicos diferenciados por referência aos padrões do continente grupal branco do qual faziam parte. Tais comentários nos remeteram ao conceito de racismo segundo Munanga 5 .

N este contexto, se enquadra a consideração do clareamento gengival enquanto técnica, despojada da consideração da questão sociorracial subjacente à qualificação do procedimento de embelezamento no plano estético.

Em meio ao desconforto que a discussão sobre a questão racial suscitou entre os entrevistados, se destaca a "neutralidade" da técnica que 0 procedimento do clareamento gengival envolve. Ratificando as disposições, foi explicitado a propósito do ensino: Queeu melembre, elenão falava nada. A cho que nem tinha que falar nada mesmo, por queiria ser contra a explicação deuma técnica? Ninguém estava agredindo ele. (Entrevistado I)

Todos os entrevistados afirmaram que eram estimulados a ofertar - no que tange à periodontia - o clareamento gengival aos pacientes portadores de melanose racial, tanto no curso de especialização como nos cursos livres, de aperfeiçoamento ou estágios, reiterando que se tratava de um procedimento estético.

N egando o viés etnocêntrico associado à concepção de beleza, a indicação da prática do clareamento gengival era estimulada junto aos pacientes, ancorada na argumentação de que, sendo 
uma característica pertencente a um determinado grupo de pessoas, não se tratava de uma doença, mas tão somente de uma prática de embelezamento. A propósito da pergunta se os entrevistados indicavam o clareamento gengival aos seus pacientes, são ilustrativas as referências sobre o estímulo da indicação do procedimento: Tudo que era de melhor para os pacientes, eles nos faziam indicar. No curso [de pós-graduação], eu fiz dois clareamentos gengivais. Ficaram lindos. Eu falava para os pacientes que não precisavam se preocupar, pois era uma característica da raça deles, mas que deveriam remover, pois era antiestético. Eles concordaram e eu fiz. (Entrevistado D)

Sempre fomos estimulados a indicar o que é 0 melhor para os pacientes. Se acreditarmos que um clareamento gengival tornará aquele pacientemais bonito, mais apresentável, por que não indicar? Éramos estimulados, sim. E é certo. Sempre avisei que não era uma doença. (Entrevistado $\mathrm{C}$ )

Reafirmando a concepção da pigmentação gengival como antiestética, sob a eficiência datécni$\mathrm{ca}$, professores de periodontia e alunos endossavam a proposição do clareamento gengival que al imenta o embranquecimento do negro na vigência da valorização do padrão branco de beleza.

\section{A prática do clareamento gengival}

Todos os dentistas entrevistados afirmaram querealizavam o clareamento gengival. Algunso faziam raramente e outros faziam cerca de um a três clareamentos gengivais por mês: Não sei te dizer exatamente quantos eu faço por mês. É raro. $\mathrm{N}$ ão são muitos, pois não atendo muitos pacientes negros no meu consultório. Você sabe qual éa realidade dos negros. Eles não têm muito acesso a dentista. Eu só atendo particular, e não sou da rede pública. (Entrevistado L)

Perguntados sobre a demanda da parte de pacientes, a mai oria afirmou queatendia poucos negros porque não trabal havam com convênios. Alguns entrevistados afirmaram que atendem al guns mulatos e negros, mas que estes não chegam a $50 \%$ dos seus pacientes.

Com o propósito de identificar se a população negra que vai ao consultório destes dentistas solicitava espontaneamente o clareamento gengival, identificamos que cerca de um quarto dos entrevistados responderam afirmativamente eos restantes afirmaram que os pacientes, em geral, desconheciam a possibilidade de clarear a gengiva: É difícil, não pedem pra fazer a melanoplastia porque eles não sabem que é possível remover as manchas. (Entrevistado O)
Os entrevistados que responderam serem procurados para a realização de tal técnica afirmaram que a justificativa apresentada pelos pacientes era que estes achavam as manchas feias ou simplesmente aspiravam ficar mais bonitos, evidenciando o desejo de embranquecer-se: Eles acham as manchas feias, se incomodam com elas, querem tirar. (Entrevistado C)

Eles dizem que querem ficar mais bonitos, se incomodam com as manchas. E é feio mesmo, né? (Entrevistado F)

Doze entrevistados declararam oferecer o clareamento gengival aos portadores de melanose racial. Questionados sobre quando e porque, dois afirmaram que ofereciam em quaisquer circunstâncias; outros o faziam quando percebiam que o paciente se preocupava com a aparência ou quando o paciente apresentava um sorriso gengival queinterferia na estética. Um entrevistado afirmou oferecer o clareamento gengival quando notava que os pacientes tinham condições financei ras de realizar o tratamento.

Todos os entrevistados compartilhavam da crença de que 0 clareamento gengival deixa os pacientes com um sorriso mais bonito, ressaltando-se que fazia parte de seu papel profissional informar aos pacientes aquilo que existe de mais moderno dentro da odontologia: Sugiro. Eles nem sempre conhecem o serviço. Eu sugiro quando o paciente tem condições financeiras de fazer e interessa. Por que eu sugiro? Para vender [risos]. U ma vez que a pessoa clareia os dentes, fica bonito. M ancha é mancha, não importa em quem está instalada. I gual nos brancos que removem manchas do rosto, por que o negro não pode remover as manchas da gengiva? (Entrevistado $\mathrm{C}$ )

Sugi ro sempre. Eu sugiro porqueéum plusque eu posso oferecer aos meus pacientes, pois nem todo dentista faz e eles ficam muito mais bonitos. (Entrevistado $\mathrm{G}$ )

Reafirmando o uso do procedimento na perspectiva etnocêntrica, é interessante observar a retroalimentação que se estabelece entre a satisfação do pacienteea admiração do profissional em relação à técnica. A maioria dos entrevistados afirmou que todos os pacientes que se submeteram ao clareamento gengival manifestavam contentamento esatisfação, expressos através de sorrisos e/ ou verbalizando o entusiasmo com o resultado final: M uito. Eles ficam parecendo crianças, tadinhos. Você precisa ver. Vocênão faz? Eles abrem um sorriso bem grande! Alguns falam quenão acreditavam queficaria tão bom. As mulheres são mais falantes. Elas ficam todasseachando o máximo. 0 clareamento déxa mesmo o paciente mais bonito. (Entrevistado A) 
M uito. Eles gostam muito dos resultados, fica realmente bom. Eu pergunto o que acharam e eles dizem que está ótimo, a gente vê a satisfação na cara deles, não precisa dizer muita coisa. (Entrevistado $\mathrm{H}$ )

Reiterando o destaque da técnica, estas falas acobertam a descaracterização de alternativas de distintas ordens de beleza, adstrita às diferenças étnicas. N esse sentido, parece que priorizavam a beleza do branco em detrimento de outros grupos "raciais". Como afirma M andarino ${ }^{14}, 0$ senso estético é influenciado pela cultura e auto-imagem; o que é considerado belo por uma civilização pode ser extremamentefeio para outra. As mulhe res obesas já representaram o padrão de beleza em determinada época, sendo que atualmente as modelos de sucesso são bastante magras.

Sem pretender justificar esses posicionamentos (afirmativos ou evasivos), solicitamos aos entrevistados que tecessem comentários relacionados às correções estéticas na população negra. N egando sumariamente o caráter racista da indicação da prática, sob os imperativos da técni$\mathrm{Ca}$, al guns entrevistados destacaram que "A área da saúde não é racista" (Entrevistado $B$ ).

Dissociando a relação entre o procedimento do clareamento gengival e sua indicação para negros, os entrevistados argumentaram que " $O \mathrm{~s}$ orientais também apresentam pigmentação na gengiva" (Entrevistado D).

Os entrevistados reafirmaram que a presença da melanose racial éantiestética, sendo significativo o depoimento: Vocêpodefalar o quequiser, dizer queeu sou racista. $M$ as se eu tivesse a gengiva pigmentada eu já teria feito o clareamento gengival. (Entrevistado C)

N uma outra vertente, explicitando a perspectiva etnocêntrica de suas concepções de bel eza, alguns entrevistados assumem que: Se os negros querem ficar parecidos com os brancos, é por queos brancos devem ser mais bonitos. (Entrevistado 0 ).

Numa variante dessa vertente, alguns entre vistados justificam a prática do clareamento gengival em função das demandas do próprio ne gro: Não éo branco que quer que o negro se pareça com ele. É o próprio negro que quer se assemelhar ao branco. (Entrevistado A)

Trata-se, nesse caso, da percepção do movimento do embranquecimento que constitui, na verdade, a contraface do preconceito explícito.

Ao justificar a realização do clareamento gengival explicitando ou negando o caráter racista do procedimento, reafirmam, em nome da técnica, a valorização do padrão branco de beleza, reproduzindo o preconceito implícito nas rela- ções sociais vigentes na sociedade, seja na perspectiva do branco como do negro.

\section{Consideraçõesfinais}

No contexto do debate nacional em torno da questão da exclusão social, na qual se inscrevem proposições como as Políticas Afirmativas ou as Reformas Curriculares, contemplando o incentivo à atuação responsável, a presente investigação enveredou no plano da identificação de posturas etnocêntricas no espaço do cotidiano da atividade profissional. Em caráter exploratório, o trabalho sinalizou, especificamente, a valorização do padrão branco de beleza na formação e na prática do clareamento gen gival, no quetange ao ensino e prática da periodontia.

A consulta aos livros-textos que apóiam a formação profissional dos dentistas evidenciou a ausência de consi deração dos diferenciais étnicos de bel eza, descortinando o espaço para absolutização do padrão branco de beleza. Em nome da supervalorização da técnica, tida como neutra, a recomendação do clareamento gengival no ensino se faz, assim, abstraída das condições sociais nas quais se inscrevem as relações dentistapaciente, obscurecendo as preferências estéticas em relação às diferenças étnicas.

Imprimindo a racionalidade biologicista que preside à saúde, o intervencionismo tecnicista particularmente no contexto da prática liberal é reforçado pela associação entre bel eza e saúde, que consubstancia a patologização das diferenças. Sem desmerecer a liberdade de acesso à técnica, legitima-se, nestas condições, a opção pelo branqueamento tanto da parte do profissional como dos pacientes negros. O mitindo ou relegando ao segundo plano a normalidade da pigmentação melânica, em meio à desconsideração da diversidade étnica de beleza, a oferta, assim como a demanda pelo clareamento gengival, alimentam a hierarquização presente nas relações sociais interétnicas de nossa sociedade.

0 clareamento gengival se inscreve no âmbito da preocupação da estética, inerente à profissão, associada ao "sorriso bonito", dimensionado em função do caráter funcional e saudável. No quadro da desconsideração das diferenças étnicas, estas concepções demarcam o espaço para posturas etnocêntricas, seja quando os profissionais parecem assumir a desqualificação da beleza negra em detrimento da branca, e/ou responsabilizam os próprios negros que demandam o clareamento gengival em nome do embran- 
quecimento, seja quando negam ou não assumem conscientementeo caráter racista que pode estar embutido na indicação do procedimento, al egando que a melanose não é exclusividade do negro ou que ela é um produto decorrente da val orização da bel eza global. Esta negação se inscreve na ausência da consideração do racismo no âmbito da cultura da cordialidade brasileira que coincidecom a absolutização da bel eza - que se reduz, nestas circunstâncias, a escolhas individuais em detrimento do reconhecimento dos padrões socioculturais.

0 clareamento gengival não é propriamente uma prática frequente - ao menos - na periodontia, atribuindo-se tal restrição ao desconheci- mento e/ou à limitação de acesso da população negra - principais demandantes do procedimento - aos serviços privados da odontologia. Apesar da limitada frequência, o clareamento gengival se constitui num caso exemplar por referência à (re) consideração do ensino na graduação em odontologia. No contexto das reformulações curriculares, ressalta-se, a propósito, a propriedade de ver tratada a questão da estética para além do senso comum. Esclarecer sua vinculação com a realidadesocial concreta ehistórica contribui para ampliar o debateem torno da exclusão social edo convívio com a diferença enquanto componentes da formação para o exercício socialmenteresponsável da prática profissional.

\section{Colaboradores}

ED Bolla participou de todas as etapas da pesquisa, P Goldenberg participou da elaboração do projeto até a confecção do presente artigo. 


\section{Referências}

1. Thomaz OR. A antropologia e o mundo comtemporâneo: cultura e diversidade. In: Silva AL, Grupioni $L$, organizadores. A temática indígena na escola. Novos subsídios para professores de 10 e $2 \stackrel{0}{\text { graus. }}$ Brasília: M EC/M ARI/U NESCO; 1995.

2. Machado FL. Os novos nomes do racismo: especificação ou inflação conceptual? Sociologia [periódico na Internet] 2000. [acessado 2007 abr 22]. Disponível em: http://www.scielo.oces.mctes.pt/scielo.php

3. Munanga K. U ma abordagem conceitual das noções de raça, racismo, identidade e etnia. In: 30 Seminário N acional Relações Raciais e Educação; 2003; Rio de Janeiro. [Palestra]

4. Carneiro ML. O racismo na história do Brasil. 8a ed. São Paulo: Ática; 2005.

5. Soligo A. 0 preconceito racial no Brasil: Análise a partir de adjetivos e contextos [tese]. Campinas (SP): Pontifícia Universidade Católica; 2001.

6. Oliveira LSR. A interdisciplinaridade e a mudanças curriculares nos cursos de graduação em O dontologia [dissertação]. São Paulo (SP): Unifesp; 2006.

7. Haag C. Quase pretos, quase brancos. Pesquisa FAPESP [periódico na Internet] 2007 abr. Disponível em: http://revistapesquisa.fapesp.br/?art $=3188 \& b d$ $=1 \& p g=1 \& \mid g=$

8. Domingues PJ. Negros de almas brancas? A ideologia do branqueamento no interior da comunidade negra em São Paulo, 1915-1930. Estud. afro-asiát. 2002; 24(3):563-599.

9. Bernardino J. Ação afirmativa e a rediscussão do mito da democracia racial no Brasil. Estud. afroasiát. 2002; 24(2):247-273.

10. Hasenbalg C. Discriminação e desigualdades raciais no Brasil. Rio de Janeiro: Graal; 1979.

11. Niskier A. LDB - A nova lei da educação. $2^{\text {a }}$ ed. Rio de Janeiro: Consultor; 1996.

12. Péret $A C A$, Lima MLR. A pesquisa e a formação do professor de odontologia nas políticas internacionais e na educação. Rev. ABENO 2003; 3(1):65-69.

13. Bertollo R, Oliveira M. A percepção do belo e a proporção divina. In: Marzola C. Fundamentos de cirurgia buco maxilo facial. [site da Internet] [acessado 2006 jul 18]. Disponível em: http://www. clovismarzola.com/textos/CAPXXXI.Pdf
14. Mandarino F. Cosmética em restaurações estéticas. [site da Internet] [acessado 2007 mar 15]. Disponível em: http://www.forp.usp.br/restauradora/ dentistica/temas/este_cosm

15. Katz C. A busca infinita. Folha de São Paulo 2007; 08 abr.

16. Gould SJ. A falsa medida do homem. São Paulo: M artins Fontes; 1991.

17. A gengiva também pode ser clareada. Plástica \& Beleza 2002; ago.

18. Lindhe J, Karring T, Lang NP. Tratado de periodontia clínica e implantologia oral. Rio de Janeiro: Guanabara Koogan; 2005.

19. Carranza Jr FA. Periodontia Clínica de Glickman. Rio de Janeiro: Guanabara Koogan; 1986.

20. Machado WAS. Periodontia clínica. Rio de Janeiro: M edsi; 2003.

21. Lascala NT. Compêndio terapêutico periodontal. São Paulo: Artes M édicas; 1999.

22. Amorim Lopes JC, Lopes RR, Silva KV, Almeida RV. Três diferentes técnicas cirúrgicas empregadas no clareamento gengival. J. bras. clin. estética odontol 2003; 4(23):80-83.

23. Rocha EPG. $O$ que é etnocentrismo. São Paulo: Brasiliense; 1999.

24. Guimarães ASA. Racismo e anti-racismo no Brasil. São Paulo: Editora 34; 1998.

Artigo apresentado em 14/11/2007

Aprovado em 21/08/2008

Versão final apresentada em 29/10/2008 